\title{
The isolated tubal torsion: an insidious pediatric and adolescent pelvic urgency
}

\author{
Carmine Noviello, ${ }^{1}$ Mercedes Romano, ${ }^{1}$ Alfonso Papparella, ${ }^{2}$ Andrea Ciavattini, ${ }^{3}$ Ascanio Martino, ${ }^{1}$ \\ Giovanni Cobellis 1 \\ 1 Pediatric Surgery Unit, Salesi Children Hospital, Ancona; ${ }^{2}$ Pediatric Surgery Unit, "Luigi Vanvitelli" University of \\ Campania, Naples; ${ }^{3}$ Obstetrics and Gynecology Unit, Università Politecnica delle Marche, Ancona, Italy
}

\begin{abstract}
Isolated tubal torsion (ITT) is a rare cause of acute abdominal pain. Preoperative diagnosis is difficult because of a lack of specific signs. Surgery is recommended to preserve the integrity of the tube. Seven patients of median age of 13 years (range 9 to 15) came to our observation for worsening abdominal pain, nausea and vomiting. On admission, all girls had blood tests and ultrasound. Laparoscopy was performed for diagnosis in all cases. The girls had one-month and one-year ultrasound and clinic follow up. In all cases diagnosis was delayed, median 66 hours after the onset of symptoms and laparoscopy showed necrosis of the Fallopian tube. In five girls a laparoscopic salpingectomy was performed. In the other two, an open salpingectomy was necessary because of pelvic adhesions. Histology showed a hemorrhagic infarction of the Fallopian tubes. At follow up all patients were asymptomatic with
\end{abstract}

Correspondence: Carmine Noviello, Pediatric Surgery Unit, Salesi Children Hospital, Via Corridoni 11, 60128 Ancona, Italy.

Tel.: +39.0715962218 .

Fax: +39.0715962316 .

E-mail: carmine.noviello@libero.it

Key words: Isolated tubal torsion; Acute abdomen; Adolescent; Laparoscopy.

Contributions: CN, RM: substantial contributions to the conception and design of the work; AP: analysis and interpretation of data for the work; AC: acquisition of data for the work; AM: revising the work critically for important intellectual content; GC: final approval of the version to be published.

Conflict of interest: the authors declare no potential conflict of interest.

Funding: none.

Received for publication: 29 August 2018.

Revision received: 18 October 2018.

Accepted for publication: 19 November 2018.

This work is licensed under a Creative Commons Attribution NonCommercial 4.0 License (CC BY-NC 4.0).

(C) Copyright C. Noviello et al., 2018

Licensee PAGEPress, Italy

La Pediatria Medica e Chirurgica 2018; 40:206

doi:10.4081/pmc.2018.206 normal ovaries, but one ovarian cyst. In the differential diagnosis of acute abdominal pain in children or female adolescents the possibility of ITT should be considered for a conservative treatment. Laparoscopy allows for definitive diagnosis and treatment.

\section{Introduction}

Isolated tubal torsion (ITT) is characterized by the rotation of the Fallopian tube around itself, without involving the ipsilateral ovary. ITT is a rare cause of abdominal pain. The incidence is one in 1.500.000 adults $^{1}$ and is less frequent in children and teenagers. ${ }^{2}$ The first description in adults was in 1890 by BlandSutton, 3 but the first pediatric case was reported by Hansen in 1922.4 Although the etiology is unknown, in the adults several predisposing factors have been identified: Youssef and Provost classified them as intrinsic factors (hidrosalpinx, hematosalpinx, tubal neoplasm and abnormal tubal peristalsis), and extrinsic factors (paraovarian or paratubal masses, post-operative adhesions, uterine enlargement due to pregnancy or tumor).5,6 Sudden changes in body position have been described as predisposing factors as well. ${ }^{7}$ In children the only predisposing factors are represented by congenital malformations, such as congenital Mullerian duct anomalies, long mesosalpinx, hydatid cyst of Morgagni. ${ }^{8}$ The diagnosis is difficult, especially at an early stage, with the possibility of losing the tube.

We report our experience in the management of ITT in children and adolescents.

\section{Materials and Methods}

From January 2005 to September 2016 we treated seven patients, median age 13 years (range: 9 to 15 years) with ITT. For all patients we retrospectively evaluated time and clinical presentation, preoperative diagnosis, physical activity, laparoscopy, surgical treatment, histology and follow up. Laparoscopic diagnosis was performed by using a 10-mm umbilical operative optic, positioned by open approach, in the supine position. Pediatric surgeons performed all the operations, but an intraoperative gynecological consultation was requested to evaluate the condition of each Fallopian tube that was removed when the surgeon and the gynecologist agreed. In case of salpingectomy, two 5-mm trocars were placed in the right and left iliac quadrant. All patients were monitored by clinical and ultrasound study performed 4 weeks after discharge and a gynecological follow up 12 months after operation. 


\section{Results}

All patients came to our observation because of acute abdominal/pelvic pain. Nausea was present in five cases and emesis in three. The pain localized in the left lower quadrant in five girls, in the right in two. Menarche was present only in two patients (aged 14 and 15 years). Three patients practiced artistic gymnastics; two other sports (Table 1). All girls had a complete blood count (mild leukocytosis in two cases and CRP elevated in three). Four of the seven patients had been evaluated at another hospital the day before. Symptoms started in median 66 hours before our evaluation (range: 90-48 hours), after which another 8 hours (range 12-3) elapsed before the surgical time. Ultrasound (US) examination showed a presence of a roundish pelvic mass in five cases and tubular in the others; a normal ovarian vascularization and structure were seen in all cases. In the first five cases a Magnetic Resonance Imaging (MRI) was performed and showed normal ovaries with dilated pelvic spiral structure in each case. Laparoscopy showed an ITT in all girls (Figure 1). The treatment for the first two cases was an open salpingectomy (Pfannenstiel laparotomy): in a patient, the left tube was tenaciously coated to ipsilateral intact ovary and in the other, the right twisted tube was too close to the uterine wall (absence of a clear cleavage plane). In the other cases a laparoscopic salpingectomy was necessary because of the poor tubal vascularization after detorsion (Figure 2). Hemorrhage and necrosis of the tube were found in all cases at histopathological study.

At follow up, the patients were asymptomatic and US examination performed at 1, 3 and 6 months after surgery showed normal ovaries in both sides, only in one case was a cystic formation at the same side of the surgery of about $1 \mathrm{~cm}$ at the first ultrasound check, which then resolved spontaneously.

\section{Discussion}

ITT is a rare cause of lower abdominal or pelvic pain in young women. ${ }^{9}$ Differential diagnosis in the pediatric and adolescent population includes acute appendicitis, pelvic inflammatory dis- ease, twisted ovarian cyst, ruptured follicular cyst, urinary tract disease and renal colic. This circumstance is extremely rare before menarche: only a few instances were accounted in this age. ${ }^{10-13}$ The right side seems to be more frequently involved (about 60\%), but in our series five patients of seven had a left ITT, consistent with some reports in the literature. ${ }^{14,15}$

Preoperative diagnosis can be difficult due to a deficiency of specific signs. The most common presenting symptom, as in our series, is pain located in the lower abdomen and sometimes the persistence of pain plays a crucial role in indicating laparoscopic exploration. The clinical presentation of pain is indicative of the affected side; our patients have experienced pain on the same side of the affected tube. Laboratory tests show no specific frameworks: leukocytosis, usually mild, with increased inflammation indexes. Ultrasound is very useful in determining the correct approach to pelvic pathology (Figure 2), but it is not easy to make a diagnosis in the early stages and experience is required. The role of CT scan or MRI is still controversial. ${ }^{16}$ MRI was very useful in

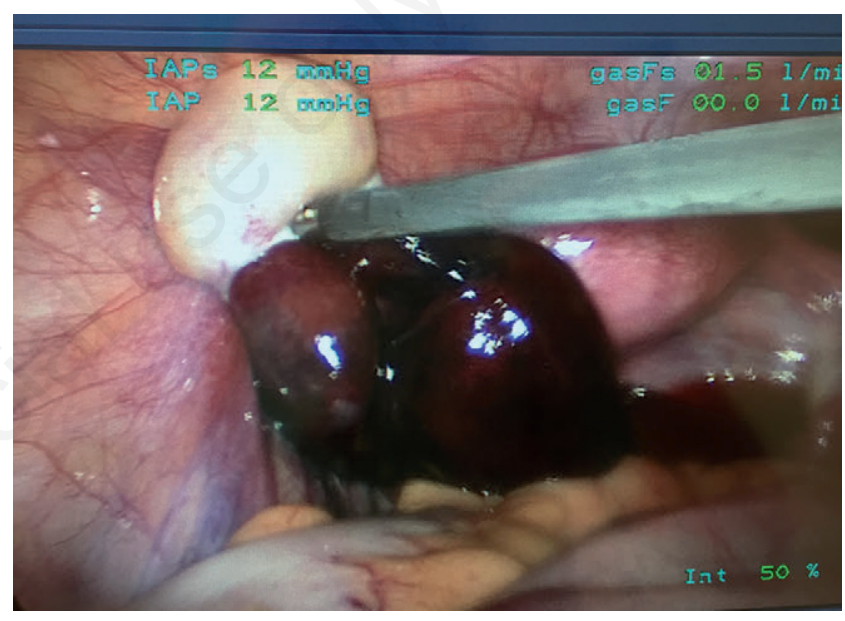

Figure 1. Laparoscopic image of the left isolated tubal torsion with normal ovarium and necrosis of the Fallopian tube in a 9year-old girl.

Table 1. Seven cases of isolated tubal torsion.

\begin{tabular}{|c|c|c|c|c|c|c|c|c|}
\hline Case & $\begin{array}{l}\text { Age } \\
\text { (year) }\end{array}$ & $\begin{array}{l}\text { Pre-operative } \\
\text { investigation }\end{array}$ & $\begin{array}{l}\text { Onset of pain } \\
\text { (hours) }\end{array}$ & Laparoscopy & Side & Sports & Procedure & Follow up \\
\hline 1 & 12 & US, MRI & 72 & Yes & Left & No & $\begin{array}{c}\text { Open } \\
\text { salpingectomy }\end{array}$ & Yes, Ok \\
\hline 2 & 13 & US, MRI & 90 & Yes & Right & $\begin{array}{l}\text { Rhythmic } \\
\text { gymnastics }\end{array}$ & $\begin{array}{c}\text { Open } \\
\text { salpingectomy }\end{array}$ & $\begin{array}{c}\text { Yes, right } \\
\text { ovarian cyst }\end{array}$ \\
\hline 3 & 14 & US MRI & 68 & Yes & Left & $\begin{array}{c}\text { Artistic } \\
\text { gymnastics }\end{array}$ & $\begin{array}{l}\text { Laparoscopic } \\
\text { salpingectomy }\end{array}$ & Yes, Ok \\
\hline 4 & 15 & US, MRI & 48 & Yes & Left & $\begin{array}{c}\text { Artistic } \\
\text { gymnastics }\end{array}$ & $\begin{array}{l}\text { Laparoscopic } \\
\text { salpingectomy }\end{array}$ & Yes, Ok \\
\hline 5 & 16 & US, MRI & 48 & Yes & Left & $\begin{array}{c}\text { Track } \\
\text { and field }\end{array}$ & $\begin{array}{l}\text { Laparoscopic } \\
\text { salpingectomy }\end{array}$ & Yes, Ok \\
\hline 6 & 9 & US & 88 & Yes & Left & Volley & $\begin{array}{l}\text { Laparoscopic } \\
\text { salpingectomy }\end{array}$ & Yes, Ok \\
\hline 7 & 13 & US & 48 & Yes & Right & No & $\begin{array}{l}\text { Laparoscopic } \\
\text { salpingectomy }\end{array}$ & Yes, Ok \\
\hline
\end{tabular}

US, ultrasound; MRI, magnetic resonance imaging. 


\section{YOUNG GIRL WITH ACUTE PELVIC PAIN}

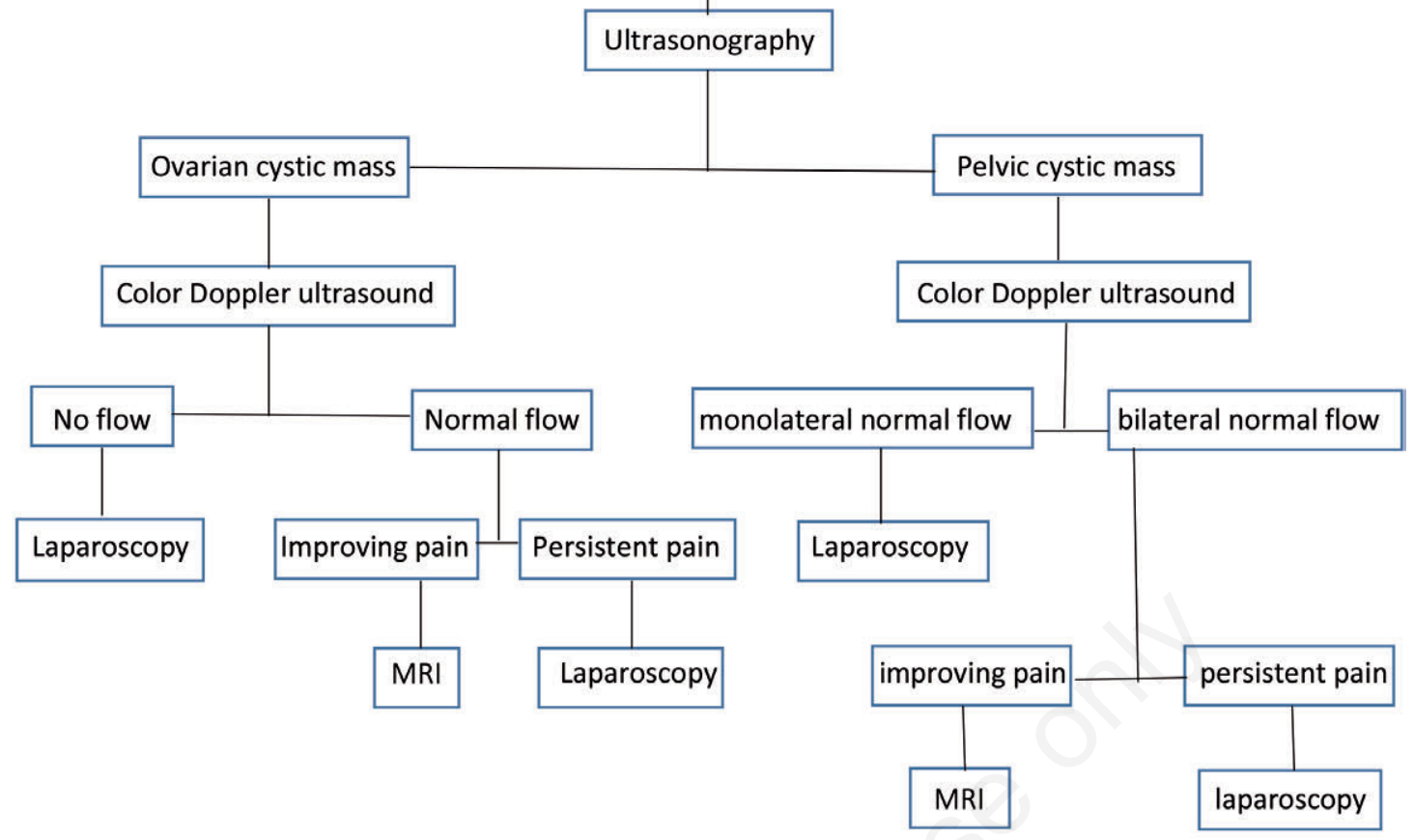

Figure 2. Decision tree that could help surgeons in decision making for young girls with acute pelvic pain. MRI, magnetic resonance imaging.

addressing the diagnosis in the first five cases, afterwards, in the other two, thanks to the experience gained, it was easier to address the diagnosis and we preferred not to perform the MRI, but laparoscopy to speed up the time. Laparoscopic examination of the pelvis is crucial in these patients because it allows a prompt diagnosis and subsequent treatment even through a single umbilical access. ${ }^{17}$ Tubal detorsion should be attempted as first line management in all cases. Resection may be considered if ischemic damage appears to be irreversible. There have been several well published reports of return of ovarian function after detorsion, as evidenced by development of ovarian follicles. ${ }^{10}$ However, clear criteria for tubal resection remains vague in the literature as long term evidence of tubal recovery remains lacking and imaging by ultrasound is not definitive. ${ }^{14}$ In cases of late diagnosis salpingectomy is necessary because of the irreversible vascular changes of the tube. Partial salpingectomy is a debated therapeutic option but some Authors report that the residual part of the tube might be the site of hydrosalpinx or ectopic pregnancy. Furthermore, laparoscopy reduces the risk of abdominal adhesions compared to an open approach, and this is very important for girl of reproductive age who wish to preserve their fertility. ${ }^{18}$

\section{Conclusions}

We want emphasize the fact that tubal torsion in adolescence is an eventuality to consider, especially in patients who practice sports with sudden body movements; clinic presentation is not very suggestive and pelvic ultrasound is the examination of first instance but in the suspicion laparoscopy allows a quick diagnosis and prompt treatment.

\section{References}

1. Shalini R, Shaili N, Neerja G. Fallopian tube torsion: a rare emergency. J Gynecol Surg 2011;27:41.

2. Casey RK, Damle LF, Gomez-Lobe V. Isolated Fallopian tube torsion in pediatric andadolescent females: a retrospective review of 15 cases at a single institution. J Pediatr Adolesc Gynecol 2013;26:189-92.

3. Bland-Sutton J. Salpingitis and some of its effects. Lancet 1890;2:1146-8.

4. Hansen A. TubetorsionmitHaematombildung und ihreaetiologie. Zentralbl Gynak 1922;46:707-8.

5. Youssef AF, Fayad MM, Shafeek MA. Torsion of the fallopian tube. Acta Obstet Gynecol Scand 1962;41:292.

6. Provost RW. Torsion of the normal Fallopian tube. Obstet Gynec 1972;39:80-82.

7. Romano M, Di Giuseppe J, Serri M, et al. A possible association between sports and isolated fallopian tube torsion in children and adolescent females. Gynecol Endocrinol 2015;31:688-92.

8. Bernardus RE, Van der Slikke JW, Roex AJ, et al. Torsion of the Fallopian tube: someconsideration on its etiology. Obstet Gynecol 1984;64:675-8.

9. Gunal YD, Bahadir GB, Boybey1 O et Al. A rare cause of acute abdominal pain in children: Isolated tubal torsion; a case series. Turk J Emerg Med 2016;17:73-6.

10. Webster KW, Scott SM, Huguelet PS. Clinical predictors of isolated tubal torsion: a case series. J Pediatr Adolesc Gynecol 2017;30:578-81.

11. Toyoshima M, Mori H, Kudo K, et al. Isolated torsion of the fallopian tube in a menopausal woman and a pre-pubertal girl: two case reports. J Med Case Rep 2015;9:258. 
12. Blitz MJ, Appelbaum H. Management of isolated tubal torsion in a premenarchal adolescentfemale with prior oophoropexy: a case report and review of the literature. J Pediatr Adolesc Gynecol 2013;26:95-7.

13. Boukaidi SA, Delotte J, Steyaert H, et al. Thirteen cases of isolated tubal torsion associatedwith hydrosalpinx in children and adolescent, proposal for conservative management:retrospective review and literature survey. J Ped Surg 2011;46:1425-31.

14. Bertozzi, M, Magrini E, Riccioni S, et al. Isolated fallopian tube torsion with hydrosalpix: Review of a debated management in a pediatric population. J Pediatr Surg 2017;52:1553-60.

15. Maynard SR, Peipert JF, Brody JM. Tubal torsion appearing as acute pelvic inflammatorydisease. J Am Assoc Gynecol Laparosc 1996;3:431-3.

16. Sakuragi M, Kido A, Himoto Y, et al. MRI findings of isolated tubal torsions: case series of 12 patients: MRI findings suggesting isolated tubal torsions, correlating with surgical findings. Clin Imaging 2017;41:28-32.

17. Cobellis G, Torino G, Noviello C, et al. Versatility of one-trocar surgery in children. J Laparoendosc Adv Surg Tech A 2011;21:549-54

18. Papparella A, Nino F, Coppola S. Peritoneal morphological changes due to pneumoperitoneum: the effect of intra-abdominal pressure. Eur J Pediatr Surg 2014;24:322-7. 